\title{
A Performative Research with The Eco-Parametric Architectural Design
}

\author{
Levent Arıdağ $\odot$ \\ Assoc. Prof. Dr., Faculty of Architecture, Gebze Technical University, Kocaeli, Turkey. Email: leventaridag@gtu.edu.tr
}

\begin{abstract}
Purpose

This study aims to see the eco-parametric design as performance research and try to reveal the relationship between nature and space and try to develop a new architectural design strategy.

Design/Methodology/Approach

The new strategy consists of three phases: Phase 1: Simulations, Phase 2: Eco-discourses, Phase 3: Modulations. The new strategy includes analytic, geometric, descriptive, qualitative research.

Findings

In the context of "performance", the grid becomes an evolutionary device and the array of a matrix placed in vertical and horizontal arrays with a mathematical set of probabilities. The grid creates an effect of operative interconnectivity on the interlinked logic of episodes and events themselves. The operative matrix works both by making the dynamic parameters in nature visible by simulation and by running this visibility as the codes of the design process. The operative matrix controls the movement in this dynamic system, allowing new design decisions to be made. Therefore, the design process turns from an analytical and logical structure to an evolutionary and intuitive structure with layers. This enables flexible adaptive variability in the space design. The name of this strategy is ECOFOLD 5.0.
\end{abstract}

\section{Research Limitations/Implications}

The dynamic model offered by performance-based research provides new production strategies for the built environment design, as well as new spaces and strategies for the construction and use of the artificial environment. It tries to design the artificial environment as a stable whole that exists with ecosystems in nature.

\section{Social/Practical Implications}

ECOFOLD (EF) becomes adaptable for different geographies. The concept of layout depending on multiple parameters can be operated. EF creates its activity with the continuity of internal and external relations crystallizing the formation of space. Crystallization can be considered here both in terms of a metaphor and geometry itself. The layers of internal and external simulations accumulate and crystallize as in a chemical reaction. These layers include the coding of the movement. The movement is encoded according to time and creates the evolutionary texture. This process results in the mapping of the texture.

Originality/Value

As a map, EF is the crystallization of the accumulated function of the environment. In EF, digital tools have possibilities to create performative commons. The common element to all these reshapings is the reconfiguring model of life itself.

Keywords: Architectural design, performance, parametricism, ecology, environment 


\section{INTRODUCTION: Organism and Environment}

Performance investigates the feedback loops between architecture and the systems it is embedded in. Isolated questions of form, process, fabrication, etc. cease to be a priori condition of architecture. Performance does not ask how a form looks like, but what it enables. Thus performance shifts the focus of interest from essence to effect (Ruby, 2003, p.476). This effect is dynamic. Understanding the environment as dynamic cycles of active ecology can offer a new perspective to develop control strategies in architectural design. Each ecosystem is selfsustainable and the nature of ecosystems, which lasts for 3.8 million years, is very high compared to the artificial ecological systems produced by people. This information, which is used for the benefit of humanity as in prosthetic (artificial) leg and organ design in biotechnology, has not been used enough in the built environment yet (Yeang, 2012). The dynamic model offered by performance-based research provides new production strategies for the built environment design, as well as new spaces and strategies for the construction and use of the artificial environment. It tries to design the artificial environment as a stable whole that exists with ecosystems in nature. Integrity like the order in the ecosystem provides a link between the visibility of cycles and science and design (Ryn \& Cowan, 2007). According to Mario Cucinella, the 1970s could not conduct experiments and analysis, so the link between science and design was limited. Today, with its analysis capacity, the invisible parts of the design like the airflow, shadow, etc. can be seen (Guzowski, 2017). This link includes the fundamental principles of performancebased design based on evolutionary strategies, along with developments in production models and computer technologies today. The performance gives mathematical properties for the production of interactive patterns with complex geometries (Arıdağ \& Cimşit Koş, 2016). The evolution process depending on these mathematical features can be explained by a four-feature structuring process the environment and organism (Lewontin, 2007).

It cannot be an organism without an environment, nor can it be an environment without an organism. First of all, organisms determine which elements of the outside world will be brought together to form their environment, and what kinds of relationships between the elements will relate to them. The environment is understood by the activities of the organism. The building can be thought a body of as an organism. An organism as a body suggests density and mass, with the attendant connotations of the body that Grange $(1985$, p.72) seeks to overcome. He adopts the word "flesh", whose sensuousness shocks us into remembering the fundamental activity of the human body: to feel the world and to house the environment in our being. If the body is seen as flesh, how place arises as the active, emergent soil of value begin to reveal themselves. First and foremost, flesh and place merge to form a matrix of value. This axiological function shifts with the domination of the environment. According to him, there would seem to be four elemental 
structures that our bodies deploy to found place: posture, orientation, feel, and comprehension. These structures are like gestures connoting the active, fleshly role of our bodily being. They are described separately but are to be understood together. Here, the body can interpret as the transformation of the body of the building with the movements of the environment, and the effects of the environment such as wind and sun.

The second interface of the relationship between the organism and the environment is the organisms not only determine which conditions of the outside world will relate to them but with the typical features of their form and metabolism, they effectively build a world around them. All terrestrial organisms, both plants, and animals, form shells that can be observed around them with simple devices. These shells contain the body's metabolic heat and warm and humid air created by water. These shell systems in organisms are similar to prosthetic (wearing) systems that must effectively integrate with the organism to which they will be attached. The organism that contains the prosthesis device is the human body to which the device is attached, and the success of the device depends on the effectiveness of the integration in the symbiotic relationship between the system and the natural organism to which it is attached. In the built environment, the carrier organism is the ecosystem. The success of the design depends on the performance of the designed system as well as the effectiveness of the integration in the symbiotic relationship between the built environment and the ecosystem in the biosphere. One of the success parameters of this effect depends on the use of renewable energy sources with passive methods. This design strategy mimics the atmosphere of the world by creating a building shell as a greenhouse with a prosthetic approach. This mimesis also includes obtaining a surface articulation that will increase the performance of the greenhouse by keeping the heat against the wind.

Third, organisms not only determine what is related to them and create a set of physical relationships between the appropriate situations of the outside world but also constantly change their environment. The carbon dioxide produced by animals is the raw material of plant photosynthesis. Thus, organisms change their environment of other species in ways that can be vital for other organisms. The symbiotic cooperation strategy in the ecosystem is a result of the interaction between different species and ecological functions. Under this strategy, organisms spread around the environment to take advantage of all kinds of functions. Thanks to the cooperation between producers, consumers, and differentiating species, each playing different roles in the ecological system, the system shows dynamic stability (Yeang, 2012). Therefore, in the building, symbiosis in the ecosystem can produce a variety of architectural programs by producing a performance.

The fourth feature of the structuring of the environment is that when organisms become part of their environment, organisms modulate the statistical properties of external conditions. Living systems can both average time and perceive proportional change. Ecosystems have many 
interaction channels. These channels provide feedback to every community, ensuring high environmental control and system-wide stability. This can view as a knowledge-based operating system. Ecosystems survive, adapt, and evolve in their natural habitat. This may also be the target of eco-parametric architectural design.

Just like in organisms, when the relationship of the building with the internal and external environment is viewed as an operating system based on information, it is ensured that the appearance of nature is obtained through wind simulation, and a new relationship model where the existing building system can be transformed by combining this information obtained from nature with the knowledge of eco-discourses is investigated methodically. In this method, on the one hand, information vectors that visualize the pressure levels obtained from wind simulation are used, on the other hand, the information of eco-discourses is thoughtfully diagrammed. As a result of these, an understanding of surface and space with advanced performance has been achieved. Because of this study aims to see the eco-parametric design as performance research and try to reveal the relationship between nature and space and ask the following questions:

What is the potential for applying digital simulation for research in ecoparametric design?

What layout concepts parameterize geometry?

How can self-sufficiency as a symbiotic system be possible in high-rise buildings?

Can the eco-parametric approach in architectural design offer a strategy for spatial transformation? What are the eco-parameters of this strategy?

\section{THEORY: Simbiotic Simulation as a Performance}

Evolutionary design is a creative process in terms of form production, architectural concepts can be determined as a series of productive rules and encrypted like codes that participate in the evolution process (Frazer, 1995). Evolutionary architecture describes processes that can develop and evolve, responding to the user and the environment, by describing architecture as an artificial way of life. Evolutionary architecture aims to create a common behavior and metabolic balance in the natural environment. For this, it directly participates in the design process of nature and behaves similarly as an organism. According to Ho (2001) seeing the building as an organism indicates that organic philosophy has been replaced by mechanical philosophy. While mechanical systems take place in space and time, organisms are mainly composed of space-time. The organism creates its spacetime by its actions. It, therefore, retains control of its space-time, and at this time it does not progress in the same way as the time in the outside world. Secondly, the organism has its entropy and mechanical systems have stability coming from a closed balance. According to him, the system functions like a non-democratic institution, it is controlled by the hierarchy. On the other hand, an organism has dynamic stability. Dynamic stability, on the other hand, is 
achieved in open systems that do not have a balance, so their entropy is high. Although the system structure develops internally, it always works with external forces and influences. In these radically democratic systems, everyone is involved in the decision making process and working environment in communication and sensitivity. Finally, a mechanical system consists of abstracted parts. Each of these parts is independent of the others. In contrast, the organism is irreducible integrity. The introduction of such basic knowledge is an important step for the biotechnology industry, which allows the development of design software used in architecture. Therefore, the development of biologybased simulation technology and coding of the invisible causes new possibilities in interdisciplinary study, and computers become an experimental environment. Thus, the parameters that provide the formation of the space and increase its performance become observable thanks to the simulations based on time. These simulations in "Performance via representation" architecture functions via its semantic associations as much as it does so via physical separation and connection. In this connection, the core competency of architecture is thus the task of articulation, which aims at an information-rich, communicative spatial morphology (Schumacher, 2016, p.110). This task of articulation can increase the performance of the space depending on the better understanding of the dynamic structure in nature. Wind motion is taken as a reference to make the invisibility visible within the scope of the performance-based research of architectural design. Therefore, with the observation of the wind movement, it is aimed to bring a new perspective in terms of spatial morphologies of tall buildings.

According to Ryn \& Cowan (2007, p.14), the heart of the ecological design is not efficiency or sustainability. It is the embodiment of animating spirit, the soul of the living world embedded in each of us waiting to be reborn and expressed in what we create and design. This soul becomes to the fore with their metaphor of the "Form follows flows". This metaphor heralds the opening of a new era like "Form follows function". A new mindset is based on a familiar concept, but the aim is to radically change the understanding of the environment and architectural form. In this context, the metaphor goes beyond criticism and develops an architecture, planning, and design strategy. This strategy rejects the approaches that glorify the form, as opposed to the conception of conventional planning and architecture. The morphological approach of the new age will be eco-morphic. With the help of computer technology, examples of this metaphoric approach in the field of planning, architecture, and design have been growing rapidly for the past twenty or thirty years. Although theorists describe these examples as new baroque architecture, revitalization of organic architecture, which characterizes form, the subject is about design strategy. The basics of this strategy should be sought in a new relationship with nature (Aymelek \& Özgencil-Yıldırım, 2015). This new eco-strategy refers to an abstract system as diagrams capable of directing operations. The operations in the 
strategy have a vertical ground. According to Zaera-Polo (2003, p.390), this type of new ground as a land strategy has specific performance:

- They are artificially constructed.

- They are neither figures nor backgrounds, but the operating system.

- They have an uncertain frame, as the field in which they exist a differentiated domain affiliated to external processes.

- They are neither a datum nor a reference.

- They are neither solid nor structured by gravity.

- They are hollow and "diagonally" structured.

This new eco-strategy is phenomena from piece to whole and from whole to piece; they are defined not as overlapping geometric forms, but as intricate connections-relationships. These relational forms are distributions of "relationships and configurations of points" and / or "sequentiality of events". This relational network is in a period between necessity and coincidence. The new strategy is not a discursive practice, but a material condition. Paying attention to the detailed conditions that determine the connection of one piece to another, it is possible to think of an architecture that can respond to differences fluently and precisely by understanding the space design as a "sequence of events" (Arıdağ, 2018). The relationships between biological concepts and ecoparametric models of the new strategy are as follows (Table 1).

Table 1. The Relationships Between Biological Concepts and Eco-parametric Models

\begin{tabular}{|c|c|}
\hline Concepts & Models \\
\hline Body of Organism & $\begin{array}{l}\text { Wind: A Body of the Nature/ } \\
\text { Aerodynamic Surface } \\
\text { Ecomimesis/ Promenade: Bodies of } \\
\text { Humans }\end{array}$ \\
\hline Shell & $\begin{array}{l}\text { Sun: A Body of the Nature/ Greenhouse } \\
\text { Social Reconnection/ Different } \\
\text { Architectural Programs }\end{array}$ \\
\hline Symbiosis & $\begin{array}{l}\text { Green Network/ Vertical Garden } \\
\text { Social Reconnection/ Different } \\
\text { Architectural Programs }\end{array}$ \\
\hline Adaptation & $\begin{array}{l}\begin{array}{l}\text { Modulation/ Topology of Surface/ } \\
\text { Texture }\end{array} \\
\end{array}$ \\
\hline
\end{tabular}

\section{PRAXIS: Towards Operational Eco-Parametric Design}

In the light of this theoretical knowledge, the strategy is developed in the Gebze Technical University Institute of Science as part of the graduate course series "Performance-based Architectural Design". The design groups are 2 or 3 students. The samples are selected from a total of 6 groups according to the differences in the designs. As part of the course, three tall buildings were selected to improve surface and space performance in Istanbul (Figure 1, 2, 3).

In the context of "performance", the grid becomes an evolutionary device and the array of a matrix placed in vertical and horizontal arrays with a mathematical set of probabilities. The grid creates an effect of operative interconnectivity on the interlinked logic of episodes and events 
themselves. An operative is a system or device capable of fostering combinatorial evolutionary developments based upon open logic. Environments generate operating actions (Gausa, 2003, p.464).

Figure 1. Design: Tekfen Tower

Figure 2. Design 2: Vadi Kule Figure 3. Design 3: Ritm İstanbul
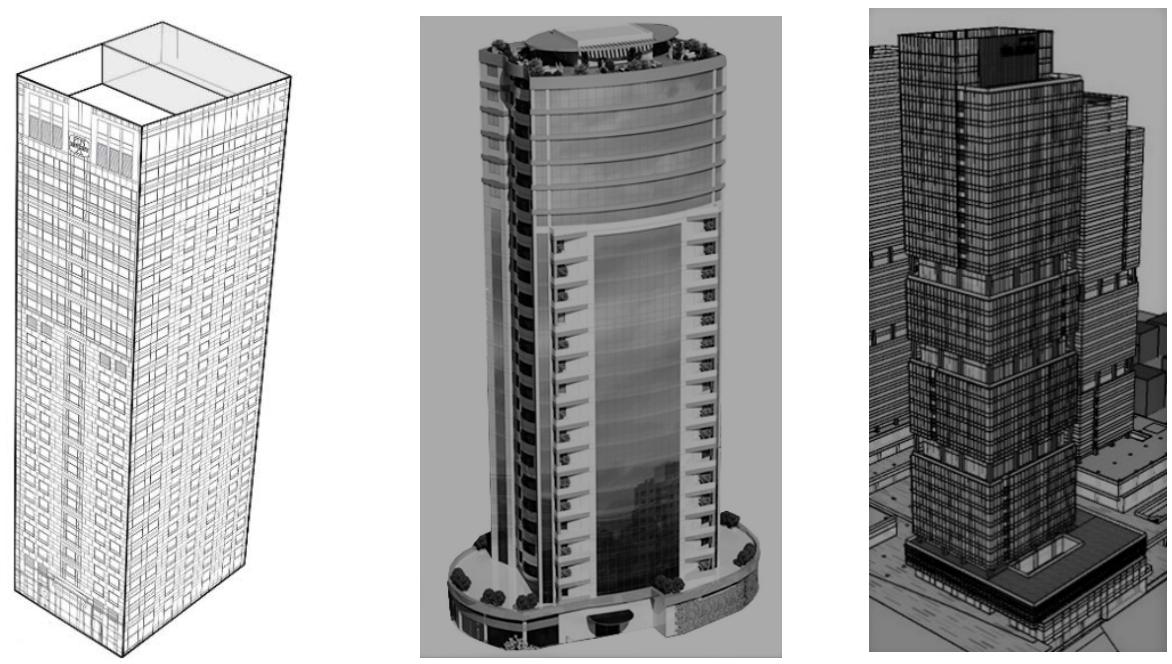

This operative matrix is necessary for digital tectonic thinking. The definitions of the digital factors for digital tectonic thinking are as follows (Mitchell, 2009, p.28):

1. Motion is the serial process of dynamic operation in the manipulation of design concepts and form evolution.

2. Information is the utilization of digital signals in any form on the skin or surface of a building as a newly appearing material.

3. Generation is the automatic generating process of form or concept by the application of software generative systems/algorithms.

4. Fabrication is the process of fabricating de design components and the method of construction with the aid of CAD/CAM technology.

Similarly, the new strategy includes these four digital factors at different levels for an operative matrix and digital tectonic thinking. As operative actions, the strategy has an operative topology. This operative topology is conceived of as and through strategic movements of folding in the environment. As the subject of performance research, it is designed as a vertical topology. Therefore, the information is encoded by simulating it with the operative matrix in the vertical. The operative matrix has different layers and they create an evolutionary system. The layers are handled until the order of chaos that students can control or the limit at which the order evolves. In the context of this system the strategy for investigating the new topology consists of three phases:

Phase 1: Simulations

Phase 2: Eco-discourses

Phase 3: Modulations

\section{Phase 1: Simulations}

Working with simulations requires the development of a logicalmathematical description of the performance of a system or process, 
which corresponds to certain specific parameters of its physical behavior. In the sciences, 'model' means more than the geometrical description of an object that we commonly use this term for. A model is an abstraction of a process and can be defined as an understanding of a process that develops, so those complex problems can be accurately modeled. Where the design ambition is to develop "responsive" architectures, buildings or artifacts that can make controlled changes to themselves to adapt to dynamic loading conditions and environmental changes, advanced simulations are essential (Weinstock \& Stathopoulos, 2006, p.59). In the context of advanced simulations, the augmentation of design projects using agent-based crowd modeling enables us to test and ascertain the enhancement of the design's social functionality; gains in operational efficiency delivered by the semiologically augmented design should become manifest via the crowd simulation. This ambitious agenda will in turn leave its innovative imprint on the very premises and tools of crowd simulation. Three key innovations are on the horizon: the generalization of crowd modeling from circulation flow simulations to a generalized life process modeling; the shift from physically conceived to communicatively conceived agents with the crucial augmentation of signor frame-dependent behaviors; and the differentiation of agents according to different social roles (Schumacher, 2016, p.112).

In the context of the crowd simulation, the current model of the selected building is created as a mass. The model is tested digitally using the "flow design" program of wind tunnel testing software of Autodesk, which creates wind simulation. While testing, the maximum blowing speeds of the wind blowing from the southwest and northeast directions in Istanbul are taken as reference. The building analyzes according to the pressure points formed with red, it is aimed to distribute these points gradually to yellow, green, blue colors that create less pressure. In the first stage, it is tried to understand what kind of geometry the topology depending on the whole building form turns into. Design 1 searches for a crystal topology to reduce the pressure effect by investigating the changes in the surface itself (Figure 4). Design 2 tries to achieve a streamlined soft topology according to the wind directions (Figure 5). Design 3 explores a new surface angle to disperse the pressure, which increases the intensity of the wind formed on the surface of the building (Figure 6).

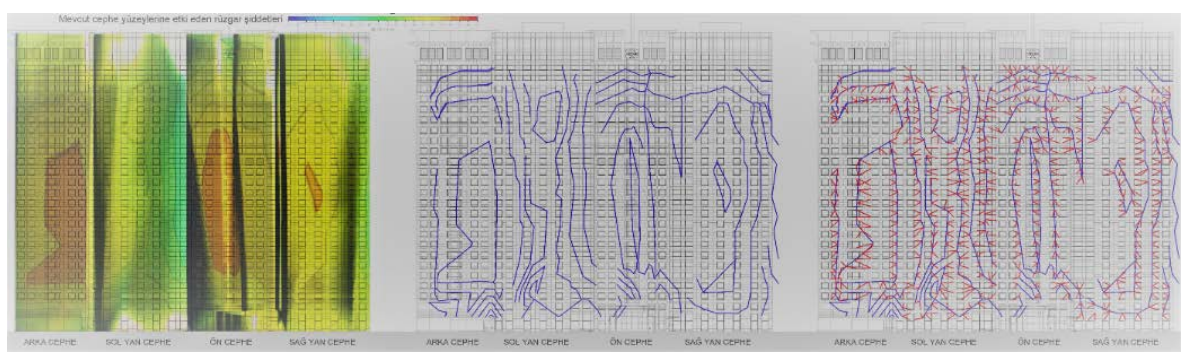


Figure 4. Design 1: Surface expansion of the current building and the proposal according to the wind effect (designed by Büşra Cantürk and Dilara Yiğit, Bioretention)
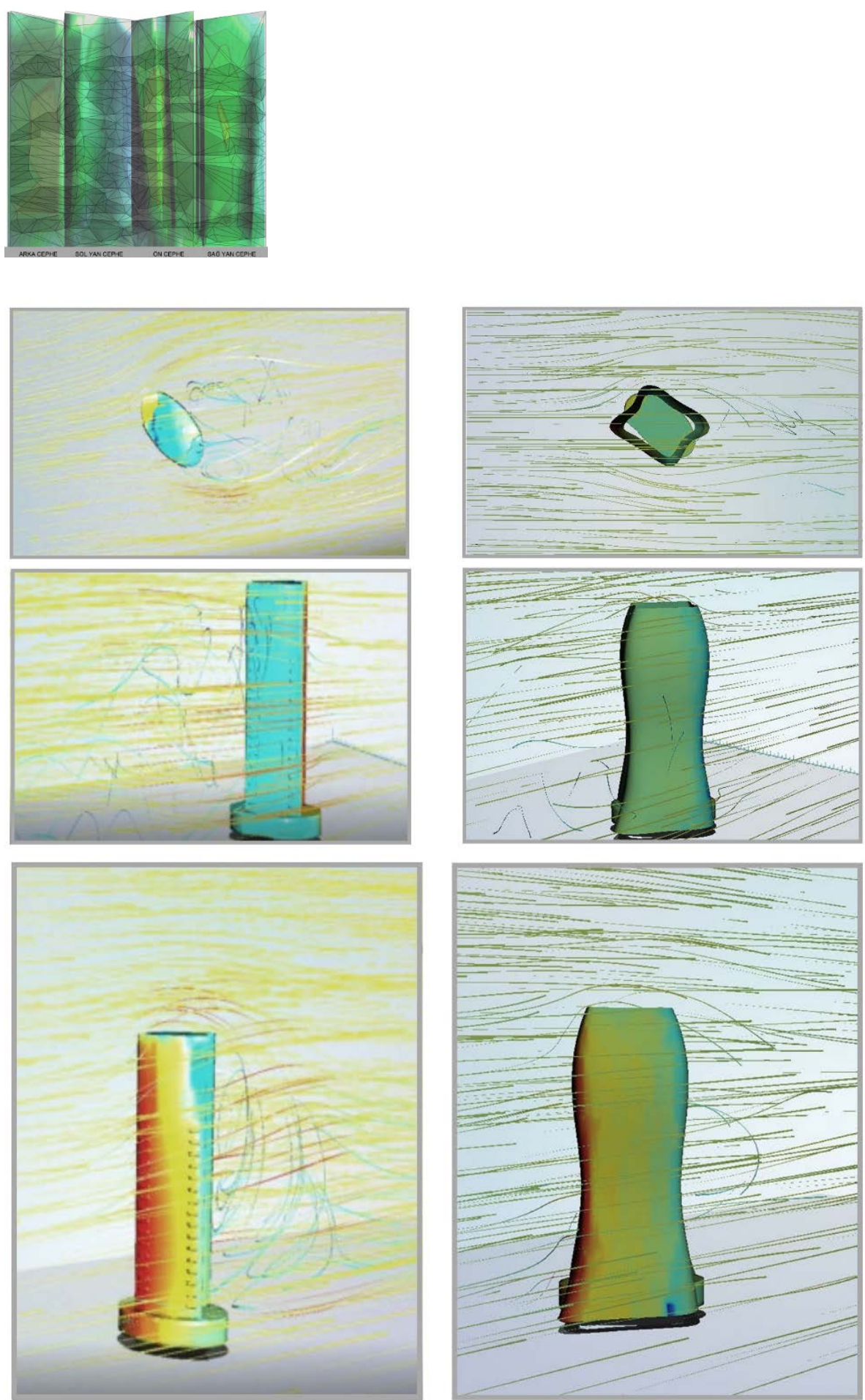

Figure 5. Design 2: Wind effects of the current building and the proposal in plan and perspective (designed by Hümeyra Damacier and Faruk Faydalı, Climesh) 


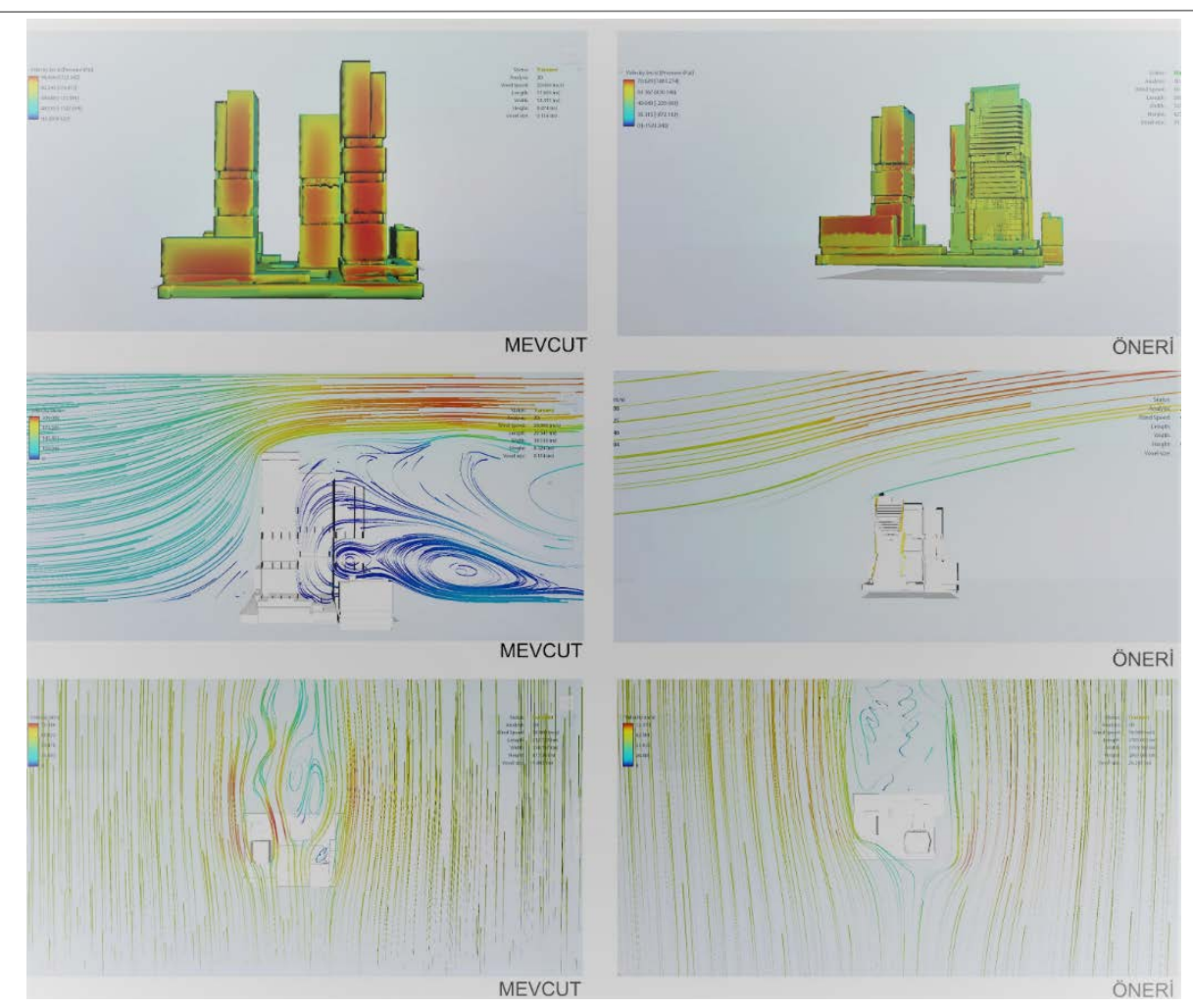

\section{Phase 2: Eco-discourses}

In the context of transformation, eco-design needs a friendly and symbiotic scenario with the eco-system in which the design field is located. In this scenario, it is important to produce discourses that establish a relationship with nature. Within the scope of this research, Ecomimesis, Green Network, Social Reconnection discourses are included.

Ecomimesis; it can be understood as a strategy that exemplifies evolution. Nature's geometry is an important organizing principle for ecological design. Geological processes operate in a self-similar way over a vast range of scales, producing a variety of fractal systems: coastlines, archipelagos, mountains, watershed drainages, fault lines, mineral deposits, and so on. Vegetation responds to these fractal landscape features, with each plant favoring a particular microclimate and set of soil conditions. Vegetation, in turn, is a major determinant of ecosystem structure and animal habitats. Fractal geological forms are ultimately reflected in fractal habitats (Ryn \& Cowan, 2007, p.59). There are many lessons to be learned from nature for designers who can observe and understand nature. Particularly, researchers who try to understand the form-structure-material relationship of structures in nature can work on optimizing their systems by using their mathematics, computer technologies, and simulation methods as tools, and increasing their communication with other disciplines (Selçuk \& Sorguç, 2007).

However, when these methods go beyond copying for designers, they find the true meaning of learning from nature by establishing relationships. The organization formed in the million-year processes inherent in eco-
Figure 6. Design 3: Wind effect of the current building and the proposal in plan and perspective (designed by Sema Kala and Beyza Partal, Fluid Empathy) 
systems is at a high level compared to artificial ecological systems produced by people. Today, there is an opportunity to mimic nature like never before. This opportunity, which is used for the benefit of humanity in biotechnology, is not yet adequately exhibited in the built environment. Nature models offered by bio and eco-mimicry, besides new production strategies for built environmental design, are the source of various methods for production and use of the built environment. When the ecosystem targets are examined, it is seen that Yeang (2012) is the target of producing an additional part of the functioning mechanism of the ecosystem. Energy flows use renewable energy efficiently in eco-systems' photosynthesis, carbon-nitrogen cycles, water, and wind energy. Ecomimicry is aimed at reducing fossil fuel consumption, using renewable energy sources.

Eco-mimesis can be considered in conjunction with bio-mimesis as the carbon cycle in the absence of the ecosystem or nature, the nitrogen cycle, and the mimicry of all the dynamics of nature. In terms of increasing spatial performance, the prosthesis is also based on the creation of the atmosphere of the world (Figure 7, 8, 9). In Design 1, greenhouses emerge on the promenade. In design $2-3$, they are constructed in the south direction connected to the floor gardens.

Figure 7. Deign 1: Ecomimesis

Figure 8. Design 2: Ecomimesis

Figure 9. Design 3: Ecomimesis
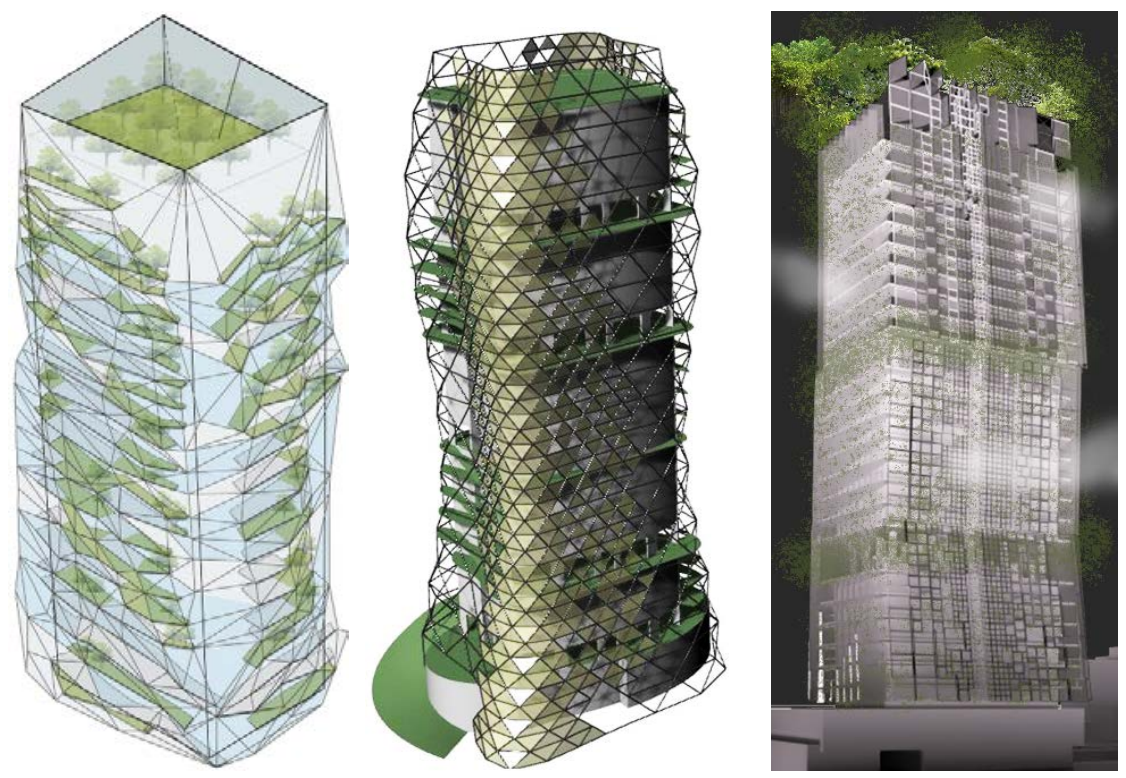

Green Network; it is aimed that green is an element of the architectural program without any rural-urban distinction. Green is associated with the body movement and architectural program. It is aimed to create a vertical promenade with a green and combine it with green textures in the city. Space is a part of this green and its continuity (Figure 10,11,12). In residential or office life, green also creates a relaxation and relaxation area. In this way, it is possible to contact green without long distances by public transportation or on foot. It also positively affects the atmosphere of space and human psychology. It continues to activate the potential of extraterrestrial natural areas through transition areas such as sports, 
culture, and relaxation as a landscape by transforming it into a new strategy. The building can be connected to the green network in the city by maintaining these green roads within its system. In all three designs, green surrounds the building in all vertical directions and on the roof. Thus, a new microclimate is created in the building. It supports this building in terms of both heating and ventilation.
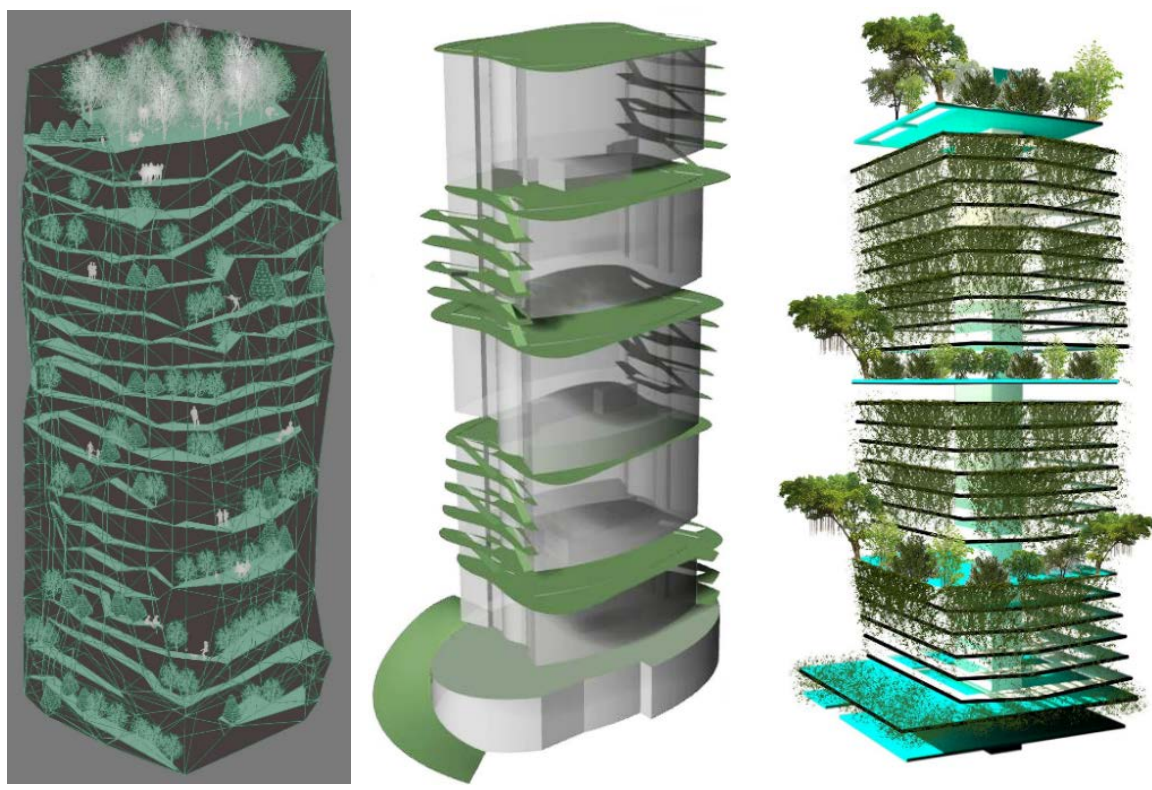

Figure 10. Deign 1: Green Network

Figure 11. Design 2: Green Network

Figure 12. Design 3: Green Network

Social Reconnection; Different action definitions that affect the system gradually as dynamic modifiers are handled together with natural forces such as wind. In the performance, also a human body can be defined as flesh as a vector whose trajectory is relative to other objects, forces, fields, flows form within an active space of force and motion (Lynn, 1999). Form as a digital tectonic can represent the transformational generation of configurative patterns. Performative interfaces as event spaces create a new interaction with public space, that they have fluidity, hybridization, complexity, and morphogenesis. If in the social context, it is desirable to plan, design or understand pluralist and ecological circles, it is important to try to balance between man and the world, feeling and thinking, experience and theory, space and environment (Arıdağ \& Cimşit Koş, 2015). This balance overall, the argument and instrumental toolset that begins to emerge operates largely on gradient threshold conditions and effects and their experiential value. In the next stage of development, it would be interesting and necessary to reengage a discourse of spatial arrangement and social formation that operates on the combination of the hard material thresholds and the environmental gradient threshold. Topological alterations of each evolved design instance may thus yield alternative and novel spatial arrangements together with the social formation pattern that these spaces can provide for (Hensel \& Menges, 2006, p.95). 
Public space can be viewed as an extension of the house. It provides an opportunity to transform the lives of these neighborhoods and to change their social relations with them. Social groups, age groups, changes of time throughout the day, and the use of promenade serve as integration of great diversity. The relationship between the people living in high-rise buildings, the places where they can socialize and the diversification of the architectural program can be designed. These places are connected with green and promenade. It supports programs that provide socialization in Design 1 by connecting promenades. In Design 1 , programs such as table tennis, sitting, eating, meditation, and library expand on the promenade, while in Design 2, programs such as a cafeteria and open-air cinema create by unloading floors and with promenade connections. In Design 3, floor spaces are mostly supported by using existing circulation as relaxation activities (Figure 13, 14, 15).
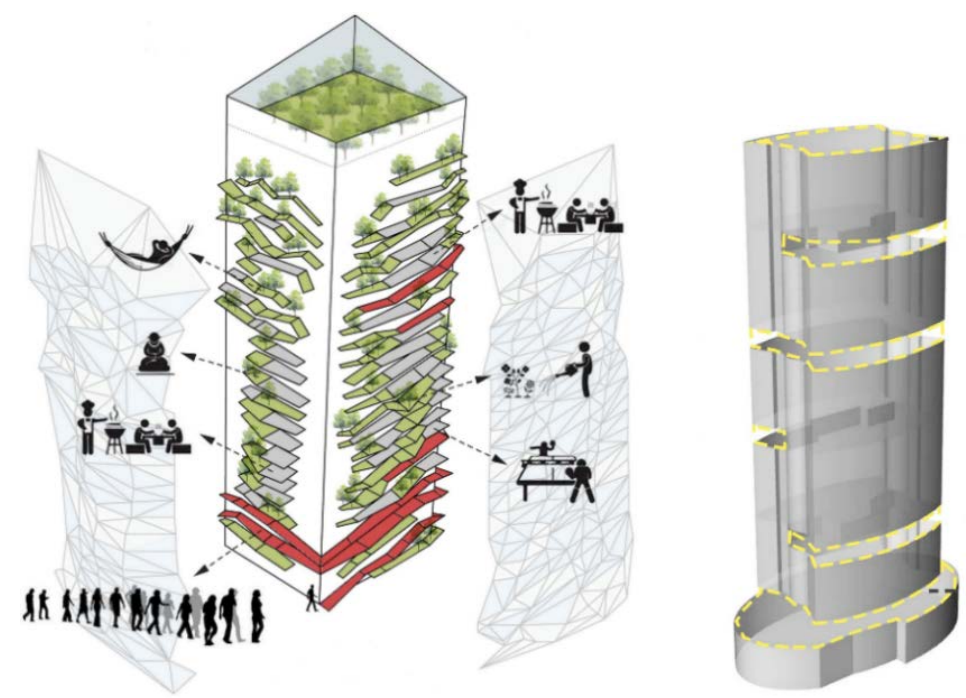

Figure 13. Deign 1: Social Reconnection

Figure 14. Design 2: Social Reconnection

Figure 15. Design 3: Social Reconnection

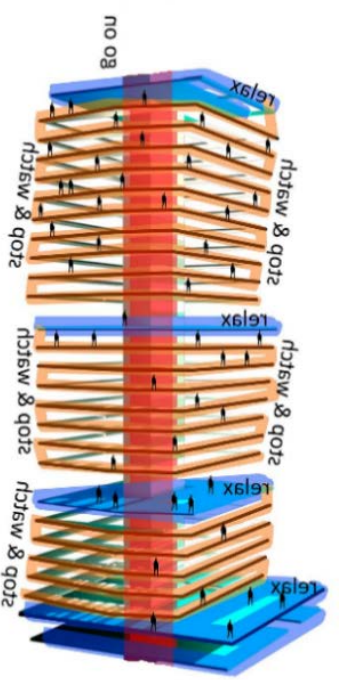




\section{Phase 3: Modulations}

Architecture as an ecology needs analytical and generative methods. That is based on strategically nested capacities within intelligence. These nested capacities as intelligence always involve selection-perception, connection-relatedness and assessment-effect and then, again, selection-perception, connection-relatedness and assessment-effect, and so on. Intelligence is a loopy process that is somewhat like a very deep algorithmic sequencing. An algorithm is a procedure for computing a defined set of relations, usually involving the repetition of an operation. Each algorithm has its behavioral refrain; it assesses the 'ifs' and 'else', and then acts, over and over. While the process of intelligence does not share the mechanical, sequential linearity of the simple algorithmic sequence, this perceived likeness underwrites the field of artificial life4 and what we call "artificial intelligence" (Ednie-Brown, 2006, p.25). The design mind that can create artificial intelligence is created by observing in the digital environment. The resulting modulation is made according to both wind simulation and ecological discourses, according to the capacity of the triangular form to form each form (Figures 16, 17, 18). Patterns with different modulation in Design 1 create a design topology, while design 2 produces a module of different sizes that are multiples of each other that make up the curvilinear topology. In Design 3, the rectangular module creates various obliques by creating different angles with the building surface.
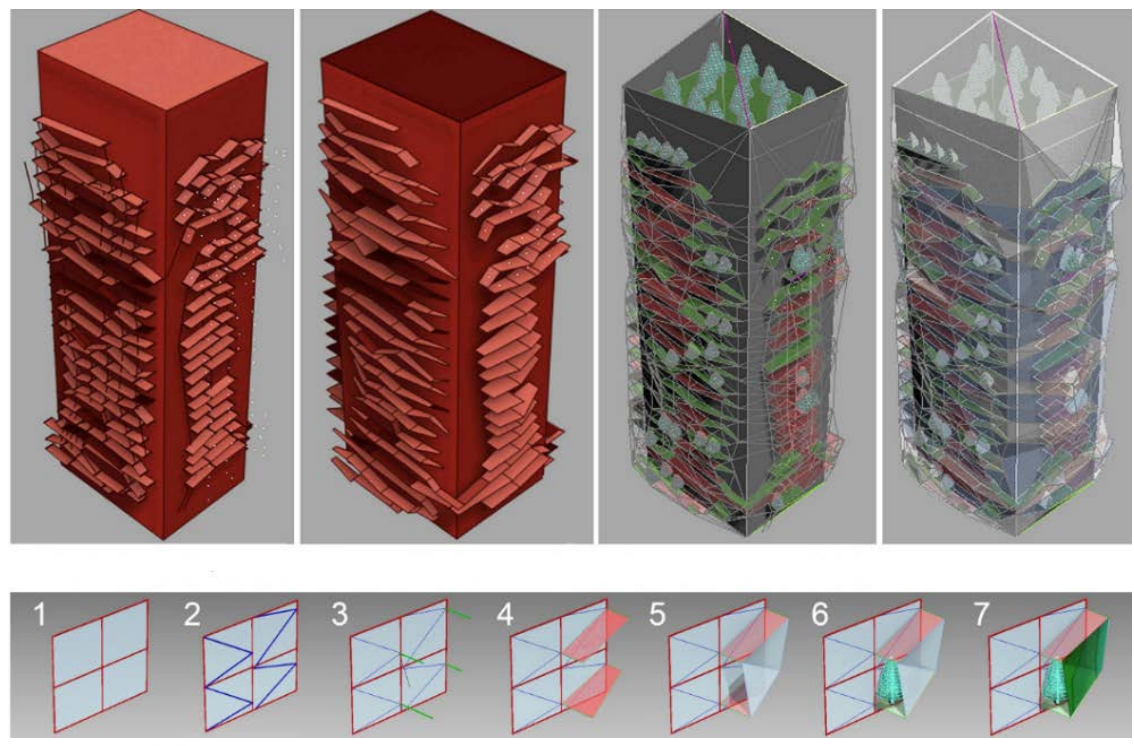

Figure 16. Design 1: Modulation

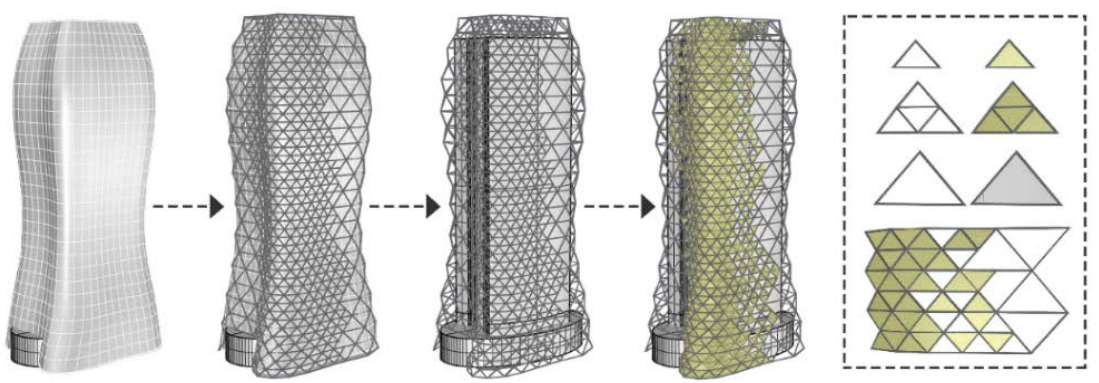

Figure 17. Design 2: Modulation 

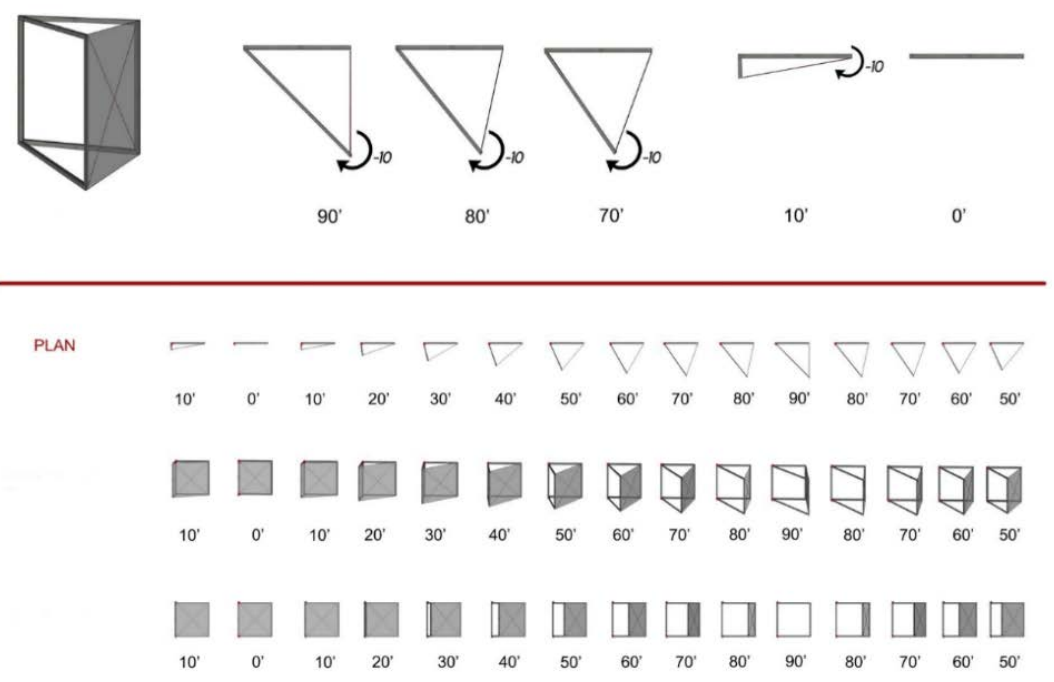

Figure 18. Design 3: Modulation
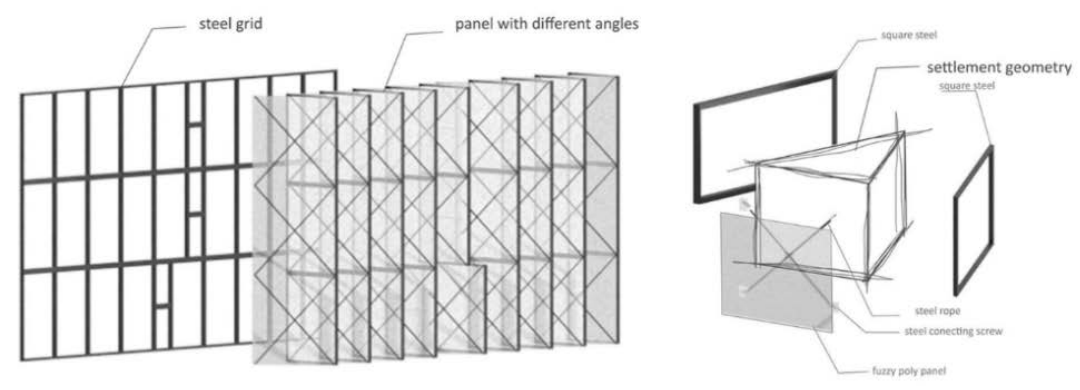

\section{CONCLUSION: ECOFOLD 5.0}

In general, the theory of evolution has taught us to recognize, measure, and simulate the complex order model that emerges from selforganization and evolutionary processes. According to Schumacher (2018), freedom was obtained by giving up the order in the $20^{\text {th }}$ century. But the parametric approach helps develop the idea of order, without giving up freedom in the $21^{\text {st }}$ century. The balance between freedom and order obtains with the operative matrix. This operative matrix works both by making the dynamic parameters in nature visible by simulation and by running this visibility as the codes of the design process. The operative matrix controls the movement in this dynamic system, allowing new design decisions. Therefore, the design process turns from an analytical and logical structure to an evolutionary and intuitive structure with layers. This enables flexible adaptive variability in the space design. The name of this strategy is ECOFOLD 5.0. Thus, ECOFOLD (EF) becomes adaptable for different geographies. The concept of layout depending on multiple parameters can be operated. The number " 5.0 " describes the version of ECOFOLD that it repeats in time and its evolution. EF creates its activity with the continuity of internal and external relations crystallizing the formation of space. Crystallization can be considered here both in terms of a metaphor and geometry itself. The layers of internal and external simulations accumulate and crystallize as in a chemical reaction. These layers include the coding of the movement. The 
movement is encoded according to time and creates the evolutionary texture. This process results in the mapping of the texture. As a map, EF is the crystallization of the accumulated function of the environment. In $\mathrm{EF}$, digital tools have possibilities to create performative commons. At the end of the process, the topological texture that was created to develop performance-based architectural design research and to better control and understand it was digitally fabricated as building surface opening on a scale of $1 / 500$ (Table 2). The common element to all these reshapings is the reconfiguring model of life itself.

Table 2. Digital Fabrication: Design 1, 2, 3

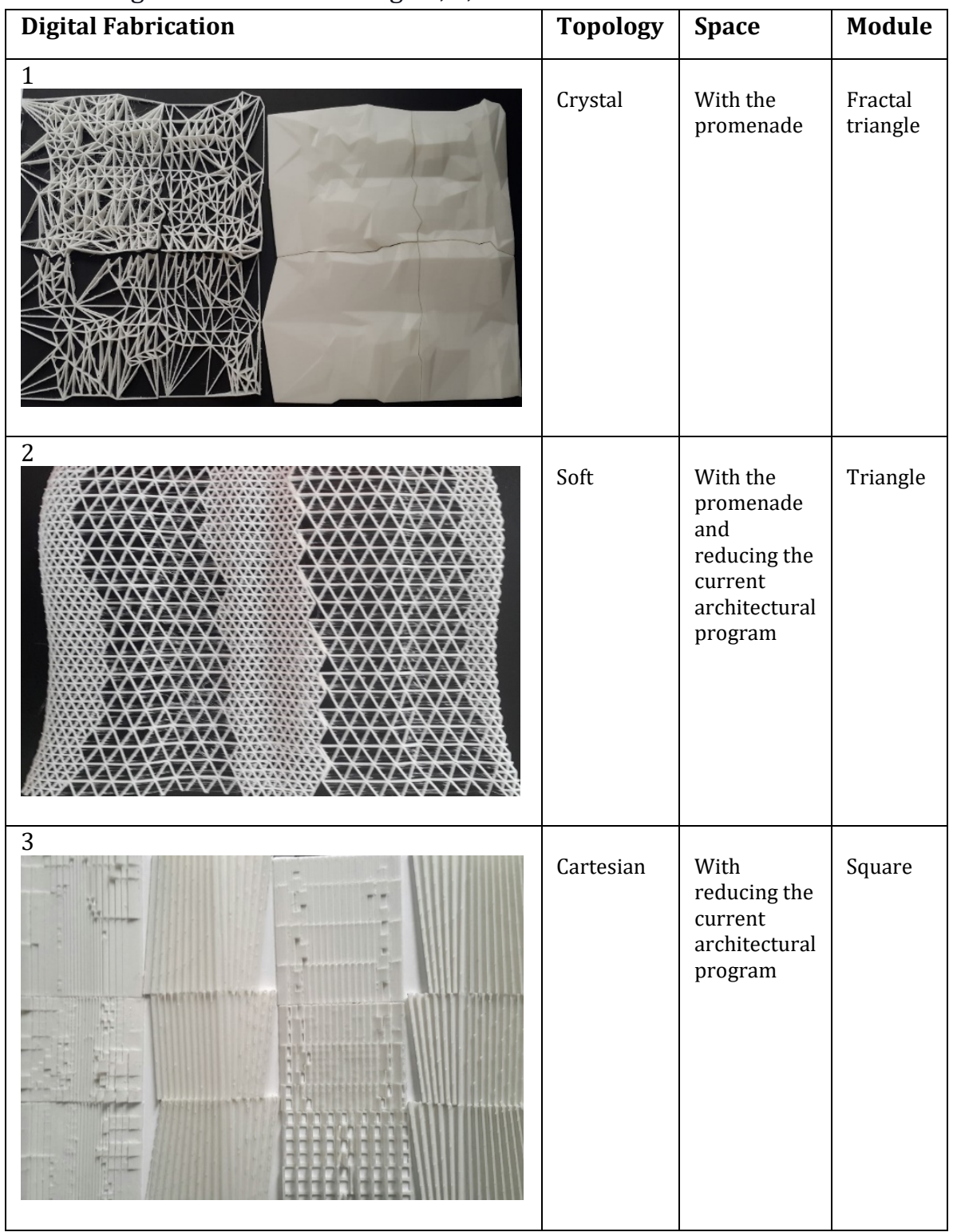

We need an understanding of environmentalism that sees humanity as a biological species closely tied to the natural world. The world is genetically our home, which has been home to millions of years of evolution of humanity and its ancestors. The wise use of the resources offered by the world is to protect the existing ecosystems and to manage 
them at a micro-level enough to save the biological diversity they contain until they can be understood and used for human benefit. In the context of this benefit and management, the topology of EF which begins to form according to the movement of the wind is associated with space, it is not only a surface. It is a folding ground that surrounds the space. This folding starts under the influence of an external force such as wind and continues to occur under the influence of internal forces such as the promenade, action, and architectural program. This formation can be continued at different scales. Today, when life changes and transforms, it can be an alternative for self-sufficient, symbiotic, and communal life. This life prioritizes both obtaining energies with greenhouses from nature, growing plants and animals, and interacting socially in this diversity. Low complexity will emerge with a strict determination, as in the case of existing buildings. Therefore, understanding the world, life, people, knowledge, and action as open systems can offer a new creative opportunity. The dialectic of interference and interaction between science-consciousness and design is not closed. Because it is at the heart of the dialectic of disorganization/reorganization that exists in this dialectic nature. This creative game can create new textures, unprecedented spaces. In this relationship, humanity can have an opportunity for a new model of life. The process of EF manifests as follows;

- Vertical topology becomes a landscape that humans can walk inside.

- The greenhouses in the landscape turn into a social space, allowing for public encounters.

- A culture that references nature as in the past is remembered and preserved.

- Space becomes an ecosystem, culture, and thought.

- Three-dimensional simulation of information increases the capacity to comment, making it possible for different disciplines to work together.

- The flexibility of the information increases thanks to the nested capacities, and the thought of the system based on the new strategy creates more sensitivity.

- Sensitivity potentially contains new technologies.

- The intelligence produced by layers with the knowledge of nature is created by computers.

- Computers work like a second mind, enhancing building performance by providing an environment of experimentation and experience for all disciplines.

- The building, which is living and adequate for the flexibility of the living function, is created with new living possibilities and ecoparametric requirements that will reconstruct society through them.

\section{ACKNOWLEDGEMENTS/NOTES}

The author has no acknowledgements or other involvements in this study. 


\section{FINANCIAL DISCLOSURE}

The author declared that this study has received no financial support.

\section{CONFLICT OF INTEREST}

No conflict of interest was declared by the author.

\section{ETHICS COMMITTEE APPROVAL}

Ethics committee approval was not required for this article.

\section{LEGAL PUBLIC/PRIVATE PERMISSIONS}

In this research, the necessary permissions were obtained from the relevant participants (individuals, institutions and organizations) during the observation.

\section{REFERENCES}

Arıdağ, L. (2018). Reconstruction of Rationality in Architectural Design: POLYFOLD 3.0. International Refereed Journal of Design and Architecture, Number: 15 Autumn Winter Semester, 45-59, Doi: 10.17365/TMD.2018.3.

Arıdağ, L. \& Cimșit Koş, F. (2016). Current Approaches in Structural Design in Case of Architectural Education. International Refereed Journal of Design and Architecture, Issue: 07 Winter-Spring, 73-84, Doi: 10.17365/TMD.2016716516

Arıdağ, L. \& Cimşit Koş, F. (2015). Regeneration of Space as a Dynamic System in the Architectural Design Studio: Alternative Beach. Mimarist Dergisi, (54): 101-105

Aymelek, Y. \& Özgencil-Yıldırım, S. (2015). Çağdaş Mimariyi Etkileyen İki Metafor: "Form fonksiyonu izler" ve "Form akışı izler". Beykent Üniversitesi Fen ve Mühendislik Bilimleri Dergisi, 8(2), 33-60

Ednie-Brown P. (2006). CONTINUUM: A Self-Engineering CreatureCulture. Architectural Design ( $A D$ ), Collective Intelligence in Design, 1825

Frazer, J. (1995). An Evolutionary Architecture. AA Publication, London

Gausa, M. (2003). Operative. The Metapolis Dictionary of Advanced Architecture, Actar- Barcelona, 464

Grange, J. (1985). Place, Body, and Situation. Dwelling, Place, and Environment: Towards a Phenomenology of Person and World (pp.71-84). Eds. D. Seamon \& R. Mugerauer, Dordrecht: Martinus Nijhoff Publishers Guzowski, M. (2017). Sino-İtalyan Ekolojik ve Enerji Verimli Binası (SIEEB). Sifır Enerji Mimarlığına Doğru/Yeni Güneş Enerjili Tasarım (pp.183-200), Yapı-Endüstri Merkezi A.Ş.

Hensel, M. \& Menges A. (2006). Differentiation and Performance: MultiPerformance Architectures and Modulated Environments. Architectural 
Design ( $A D)$, Techniques and Technologies in Morphogenetic Design, 6069

Ho, MW. (2001). The New Age of the Organism in Architecture and Science. Architectural Design Series (ed. Di Cristina, G.) John Wiley \& Sons, London

Lewontin, R. (2007). Üçlü Sarmal/Gen, Organizma ve Çevre. TÜBİTAK, Ankara

Lynn, G. (1999). Dirim Zaman. Anytime Konferans Bildirileri Kitabı, Cynthia C. Davidson, Mimarlar Derneği 5, Ankara, 274-279

Mitchell, W.J. (2009). Foreword/Antitectonics: The Poetics of Virtuality. New Tectonics/Toward a New Theory of Digital Architecture: $7^{\text {th }}$ Feidad Award, Birkhaeuser Verlag, AG, 10-18

Ruby, A. (2003). Performance. The Metapolis Dictionary of Advanced Architecture, Actar-Barcelona, 476

Ryn, S. \& Cowan S. (2007). Ecological Design.10th anniversary ed. Island Press

Schumacher, P. (2016). Advancing Social Functionality Via Agent Based Parametric Semiology. Architectural Design (AD), Parametricism 2.0, 108112.

Schumacher, P. (2018). Design as Second Nature. Published in: Zaha Hadid Architects - Diseno como segunda naturaleza, Exhibition catalogue: MUAC - El Museo Universitario Arte Contemporaneo, Mexico City

Selçuk, S.A. \& Sorguç, A.G. (2007). Mimarlık Paradigmasında Biomimesis'in Etkisi. Gazi Üniversitesi, Mühendislik Fakültesi Dergisi, Cilt 22, No:2, 451-459

Weinstock, M. \& Stathopoulos, N. (2006). Advanced Simulation in Design. Architectural Design (AD), Techniques and Technologies in Morphogenetic Design, 54-59

Yeang, K. (2012). Ekolojik Tasarım Rehberi. YEM Yayın-193, İstanbul

Zaera-Polo, A. (2003). Landstrategy. The Metapolis Dictionary of Advanced Architecture, Ingoprint SA, Barcelona, 390.

\section{Resume}

Levent Arıdağ is designer and educator, who is dedicated to develop an innovative approach towards architecture, urbanism, design and ecologie. His work aims to develop the relational thinking capacities of the architecture in its relation with design technologies. He investigates the possibilities of physical environment through the potential relations between space and time.

Web: www.leventaridag.com 